\title{
Literacy-appropriate educational materials and brief counseling improve diabetes self-management
}

\author{
Andrea S. Wallace ${ }^{\mathrm{a}}$, Hilary K. Seligman ${ }^{\mathrm{b}}$, Terry C. Davis ${ }^{c}$, Dean Schillinger ${ }^{\mathrm{b}}$, Connie L. \\ Arnold $^{\mathrm{C}}$, Betsy Bryant-Shilliday ${ }^{\mathrm{d}}$, Janet K. Freburger ${ }^{\mathrm{e}}$, and Darren A. DeWalt ${ }^{\mathrm{d}, e,{ }^{*}}$ \\ Darren A. DeWalt: darren_dewalt@med.unc.edu \\ aUniversity of New Mexico, College of Nursing, Albuquerque, NM, USA \\ bUniversity of California San Francisco, School of Medicine, San Francisco, CA, USA \\ 'Louisiana State University, Health Sciences Center, Shreveport, LA, USA \\ dUniversity of North Carolina at Chapel Hill, School of Medicine, Chapel Hill, NC, USA \\ eUniversity of North Carolina at Chapel Hill, Cecil G Sheps Center for Health Services Research, \\ Chapel Hill, NC, USA
}

\begin{abstract}
Objective-In this pilot study, we evaluated the impact of providing patients with a literacyappropriate diabetes education guide accompanied by brief counseling designed for use in primary care.
\end{abstract}

\begin{abstract}
Methods-We provided the Living with Diabetes guide and brief behavior change counseling to 250 English and Spanish speaking patients with type 2 diabetes. Counseling sessions using collaborative goal setting occurred at baseline and by telephone at 2 and 4 weeks. We measured patients' activation, self-efficacy, diabetes distress, knowledge, and self-care at baseline and 3month follow-up.
\end{abstract}

\begin{abstract}
Results-Statistically significant ( $p \leq 0.001)$ and clinically important (effect sizes $=0.29-0.42$ ) improvements were observed in participants' activation, self-efficacy, diabetes-related distress, self-reported behaviors, and knowledge. Improvements were similar across literacy levels. Spanish speakers experienced both greater improvement in diabetes-related distress and less improvement in self-efficacy levels than English speakers.
\end{abstract}

\begin{abstract}
Conclusion-A diabetes self-management support package combining literacy-appropriate patient education materials with brief counseling suitable for use in primary care resulted in important shortterm health-related psychological and behavioral changes across literacy levels.
\end{abstract}

Practice implications-Coupling literacy-appropriate education materials with brief counseling in primary care settings may be an effective and efficient strategy for imparting skills necessary for diabetes self-management.

(C) 2008 Elsevier Ireland Ltd. All rights reserved.

"Corresponding author at: Division of General Internal Medicine, 5039 Old Clinic Building, CB\#7110, Chapel Hill, NC 27599, USA. Tel.: +1 919966 2276; fax: +19199662274.

Disclosure statement: Four of the authors have advised the American College of Physicians Foundation on their program activities. DS, DAD, and TCD have each served on committees for the Foundation in the past or currently. None of the authors receive royalties or payment for use of the Diabetes Guide described in this paper.

Appendix A. Supplementary data: Supplementary data associated with this article can be found, in the online version, at doi:10.1016/ j.pec.2008.12.017. 


\section{Keywords}

Patient education; Literacy; Diabetes; Self-care; Health promotion

\section{Introduction}

Although medical innovations continue to improve the quality of chronic illness care, patients assume the responsibility for implementing recommendations on a daily basis. Unfortunately, patients are frequently not taught the complex skills necessary to manage their disease in their homes, workplaces, and communities [1,2]. Consequently, recent models of chronic illness care emphasize the importance of patient-centered selfmanagement support [3,4].

In order to manage their disease in the context of their daily lives, many patients with diabetes need support in acquiring and applying practical knowledge, setting realistic goals, and problem solving. This support must also attend to patients' literacy and culture to help ensure they can understand and apply self-management information [5-7]. Moreover, aiding patients in enhancing their self-management requires consideration of their self-efficacy and motivation to engage in diabetes self-care activities [8-12].

To provide a practical structure for self-management support in primary care clinics, we created a self-management support package which included a literacy-appropriate education guide, entitled Living with Diabetes, with a brief counseling intervention to actively engage patients in their diabetes care. The purpose of this pilot study was to assess the impact of combining the guide with brief counseling in primary care clinics. We hypothesized that the intervention would decrease patients' distress and increase patients' diabetes knowledge, self-efficacy, and motivation, and improve diabetes self-management behaviors across literacy levels.

\section{Methods}

\subsection{Material development}

The patient-centered Living with Diabetes guide and accompanying brief counseling intervention were developed by an interdisciplinary team of clinician researchers with input from patients and providers. The guide addresses topics identified by patients and providers as most important, including diet, physical activity, blood glucose monitoring, medication adherence, and insulin use. It was designed to be easily understandable across literacy levels by using plain language, a conversational tone, limited information, and pictures to convey and clarify important content. Iterative cognitive interviews with patients and providers helped ensure the guide was appealing, easily understandable, and useful.

The self-management support package, including the guide and brief behavioral counseling, was grounded in social cognitive theory. Using social cognitive theory principles, we hoped to teach behavior change skills by modeling the creation of small, personally relevant and immediate goals for behavior change. Pictures of patients illustrating practical tips and a "You Can Do It" page at the end of each chapter were included to facilitate problem solving and goal-setting skills. For more detailed discussion of the materials development, see ref. [13].

\subsection{Sample}

The study was conducted between August 2006 and June 2007 in three academic internal medicine practices in California, Louisiana and North Carolina. Patients were referred to the 
study by their health care providers and interviewed by trained research assistants in the clinical setting. Eligible participants included English and Spanish speaking patients aged $\geq 18$ years who had a type 2 diabetes diagnosis and could be contacted by telephone. We excluded patients who, according to their referring health care provider, were not responsible for, or capable of, managing their own diabetes care (e.g. residents of skilled nursing facilities, those with significant cognitive impairments). All Spanish-speaking patients were recruited from the California site.

Participants' literacy was assessed pre intervention. Pre- and post-structured interviews used a battery of five tests assessing participants' activation, distress, self-efficacy, engagement in their care, and knowledge. In addition, one site (NC) recorded the time required for each phase of counseling. Goal-setting, problem solving, and self-reported behavior change are reported in another paper.

\subsection{Measurement instruments}

We used structured interviews to determine participants' sociodemographic characteristics (age, gender, race, years of education, insurance status and length of time with diabetes). Participants' last available BMI and hemoglobin $\mathrm{A} 1 \mathrm{C}(\mathrm{HbA} 1 \mathrm{C}$, mean $=76$ days before recruitment) were collected through clinical information systems.

Activation, self-efficacy, diabetes distress, and self-care were measured with four orally administered instruments. All were validated scales providing Likert-type responses. For ease of interpretation, we converted raw scores to a 100 point scale. Higher scores indicate better activation and self-efficacy, greater distress, and improved diabetes self-care behaviors. We assessed diabetes-related knowledge using a series of free-response questions created to reflect the guide's content.

2.3.1. Patient activation-We used the Patient Activation Measure (PAM), a 13-item measure of participants' knowledge, skills, beliefs, and behaviors. A high score on the PAM suggests respondents are aware of, and involved in, preventive actions related to their own care $[11,14]$.

2.3.2. Diabetes-related distress-The Diabetes Distress Scale (DDS) is a 17-item measure of diabetes-related emotional distress [15]. It has four subscales corresponding to emotional burden, physician-related distress, regimen distress, and diabetes interpersonal distress.

2.3.3. Self-efficacy-Diabetes self-efficacy was assessed using an eight-item measure asking respondents to rate their confidence in their ability to perform individual diabetes self-care activities, such as monitoring their blood glucose, getting medical attention, and taking care of their health [16].

2.3.4. Diabetes self-management activities-We used a five-item scale asking participants to rate their ability to manage their medications, monitor their blood glucose, maintain a diet, exercise, and conduct foot care [17].

2.3.5. Knowledge—Diabetes knowledge was assessed with a nine-item instrument developed by the authors to reflect the guide's content (see Appendix A). Open-ended questions ranged from general knowledge about diabetes ("Diabetes can harm what parts of your body?") to specific actions to be taken in the event of hypoglycemia ("What are some steps to treat low blood sugar?"). For participants taking insulin, we asked two additional insulin-specific questions. Two content experts (ASW and BBS) scored responses as correct 
or incorrect (Kappa 0.90). Overall scores are presented as the percentage of questions answered correctly.

2.3.6. Literacy-Patient literacy was assessed pre-intervention using the short version of the Test of Functional Health Literacy for Adults (S-TOFHLA) $[18,19]$. The S-TOFHLA is a reading comprehension test commonly used in health care settings. It is highly correlated with tests used in general education such as the revised Wide Range Achievement Test ( $r=$ $0.74)$ [20] and with scores on the rapid estimate of adult literacy in medicine (REALM) $(r=$ 0.84 ) [21]. The S-TOFHLA is scored on a scale of 0-36 with a score of 23-36 indicating adequate literacy, 17-22 indicating marginal literacy, and 0-16 indicating inadequate literacy $[18,19]$. Because we hypothesized that the effects of literacy would persist into the marginal range, we pre-specified that the marginal and inadequate groups would be combined for analysis.

\subsection{Intervention}

The intervention consisted of an in-person introduction to the guide and brief counseling session, and two brief counseling sessions by telephone. All patient contacts were conducted by research assistants (RAs). RAs from all three sites were trained in a 1-day, in-person session led by the study team's clinician-investigators. RA training focused particular attention on interviewing and patient-centered goal setting, using the materials and techniques published by Lorig [22] and Bodenheimer et al. [23].

\subsubsection{Initial contact and baseline data collection-In each case, the RA obtained} informed consent and administered the literacy assessment, sociodemographic survey, and battery of five surveys. The RA then introduced the Living with Diabetes guide, briefly reviewed its contents, and focused particular attention on the goal-setting pages at the end of each chapter. Modeling our intervention after that described by Lorig [22], RAs asked participants to identify the domain of diabetes self-care - eating, exercise, taking medications, testing blood sugar, or taking insulin - on which they would like to focus. Participants were aided in identifying one concrete and achievable goal, or "action plan," for improving their diabetes self-management. Participants were then asked to rate their confidence in their ability in complete their Action Plans on a scale from 0 to 10. Using the behavior change model described by Bodenheimer [23], RAs encouraged those who rated their confidence lower than 7 to engage in additional problem solving in order to make their action plans more easily achievable [23]. We viewed participants' completion of action plans, and the confidence engendered by that success, as a critical element of the intervention. See Table 1 for an outline of the action plan process used during the intervention.

2.4.2. Two and four weeks after initial visit-Approximately 2 and 4 weeks after the initial visit, RAs contacted participants by telephone. Using semi-structured interviews, RAs assessed how participants had used the Living with Diabetes guide and determined progress with their most recent action plan. RAs then facilitated participants' plans for sustaining and creating additional action plans. RAs also helped participants identify and find solutions for overcoming self-management barriers that limited completion of their action plans.

2.4.3. Twelve to sixteen weeks after initial visit-Either during an office visit or by telephone, RAs conducted an exit interview which included each of the post-test surveys and assessment of participants' experience with the guide and clinical intervention. 


\subsection{Analyses}

All analyses were conducted using Stata version 9.2. Descriptive statistics were generated for the demographic and health-related characteristics of the sample. Independent $t$-tests and chi square statistics were generated to identify differences between participants who completed the study and those who were lost to follow up. Differences in the means of the outcome measures pre and post intervention were assessed using paired $t$-tests. Change scores (i.e. difference between pre and post outcomes) were also calculated for each outcome measure and were used to calculate standardized effect sizes (mean of change scores/S.D. of change scores) and to conduct analyses by literacy (adequate vs. inadequate/ marginal), and language (English vs. Spanish). Differences in mean change scores by literacy and language were assessed using independent $t$-tests.

\section{Results}

\subsection{Participants}

Two hundred and fifty patients with type 2 diabetes ( 80 from CA, 85 from LA and 85 from NC) agreed to participate (Table 2). Most were racial and ethnic minorities (45\% were African-American and 33\% Hispanic) and female (65\%). Almost half of the participants were uninsured, did not finish high school, and demonstrated less than adequate literacy. Study patients communicated extensive experience with their diabetes, with an average length of time since diagnosis of 9 years.

\subsection{Completion of intervention}

Most patients (92\%) participated in all four planned study contacts (baseline and 2, 4, and 12-16 weeks). Of the 20 participants who did not complete the study, 10 missed the 2-week call, 8 missed the 4-week call, and 2 missed the 12-16-week exit interview. Patients who did not participate in all study contacts were younger (51 years vs. 56 years, $p=0.01$ ), more educated (12 years vs. 10 years, $p=0.03$ ), had higher literacy levels ( $75 \%$ vs. 55\% with adequate literacy, $p=0.04$ ), and were more likely to be African-American ( $70 \%$ vs. $43 \%, p$ $=0.01)$ than those participating in all study contacts. They were also less likely to be Hispanic ( $15 \%$ vs. $35 \%, p=0.04)$, to have a regular physician $(35 \%$ vs. $65 \%, p=0.003)$, and to have Medicare insurance ( $5 \%$ vs. $25 \%, p=0.02$ ). Individuals lost to follow-up also had higher baseline PAM scores (77 vs. 72, $p=0.03$ ).

Data collected at the NC site showed that the baseline intervention lasted approximately 15 $\min$ and the telephone contacts averaged $14 \min (5-30$, S.D. $=4.3)$. The mean number of contact attempts per telephone interview was 1.7 (1-6).

\subsection{Changes in measures}

We observed statistically significant $(p \leq 0.001)$ and clinically important changes in participants' knowledge, self-efficacy, activation, and self-reported behavior from baseline to study completion (Table 3 ). In addition to significant reductions in total diabetes distress reported in Table 3 , changes were seen in two of the four subscales - emotional distress (mean change $=-1.85$, effect size $0.31, p<0.001$ ) and regimen-related distress (mean change $=-2.72$, effect size $0.49, p<0.001$ ).

\subsection{Differences by literacy and language}

Participants with marginal or inadequate literacy experienced similar improvements as participants with adequate literacy (Table 4). However, differences in improvement among the English and Spanish speakers varied (Table 5). Overall diabetes distress declined more for Spanish-speakers than for their English speaking counterparts ( -8.3 vs. $-3.8, p=0.03$ ). 
This relationship was primarily driven by greater reductions in the emotional distress subscale among Spanish speakers compared to English speakers ( -3.1 vs. $-1.3, p=0.03$ ). Self-efficacy levels improved only for English speakers. Self-care improvement for English speakers was also greater and approached significance (6.9 vs. 3.0, $p=0.05$ ).

\section{Discussion and conclusion}

\subsection{Discussion}

Our literacy-appropriate self-management support package, which included the Living with Diabetes guide and brief behavior change counseling, produced important improvements in patient knowledge, activation, self-efficacy, diabetes distress, and self-care behaviors. Two aspects of this feasibility study are particularly relevant to population-based strategies for improving diabetes care. First, its effectiveness across literacy levels has important implications for addressing literacy-related gaps in diabetes self-management. Second, the brevity of our intervention suggests its potential for use in primary care settings.

We found similar gains in outcomes for those with adequate and low literacy, suggesting that our strategy to reduce the complexity of self-management and our focus on behavior change - rather than on knowledge acquisition - may help mitigate literacy-related barriers. Because other studies using patient-centered, low literacy print or multi-media materials have been ineffective in increasing knowledge and/or self-efficacy of patients with low literacy $[24,25]$, we did not rely solely on the written materials to achieve these results and believe that the brief counseling included in our intervention (i.e. goal setting and problem solving) was essential for teaching the self-management tasks and behavior change skills addressed in this study.

The results of our intervention are consistent with other studies suggesting that goal setting is feasible and effective in vulnerable populations [26-28], and that disease-related education can improve self-management for those with low-literacy [29,30]. In addition, the health-related psychological and behavioral changes resulting from our brief intervention are comparable to other interventions incorporating much more intensive strategies. The magnitude of the improvement we observed in patient activation is similar to that observed in an intervention incorporating $15 \mathrm{~h}$ of chronic illness support classes over a 6-week period [14,31]. Likewise, the magnitude of improvements we observed in self-efficacy, selfmanagement, diabetes knowledge, and empowerment was similar to studies incorporating $12-15 \mathrm{~h}$ of patient education over $5-6$ weeks $[32,33]$. Therefore, our results suggest that our intervention may be efficient enough for use in primary care settings without significant loss of effectiveness.

The efficiency and effectiveness of this intervention make it particularly suitable for dissemination into primary care practices, where the majority of diabetes education takes place [34]. The ways in which diabetes education is currently provided in primary care practices is rarely effective in helping patients change behaviors [1]. This may be a result of diabetes education assuming a medical model in primary care settings, focusing on the severity of the disease and associated health risks rather than on how to help patients practically manage the disease in the context of their daily lives. In contrast, our counseling focused on teaching patients how to set achievable goals and how to overcome barriers to behavior change skills that - while emphasized by chronic illness experts - are commonly missing from clinical care [2,35].

Dissemination of this intervention into busy primary care practices may be limited by its use of behavioral counseling and repeated patient follow-up. To mitigate barriers to implementation in primary care settings, we designed each goal-setting session to be 
completed within $15 \mathrm{~min}$. We also relied on non-professional research assistants, briefly trained in diabetes self-management goal setting, to introduce the educational materials to patients, to help patients create achievable action plans, and to provide ongoing support. Our success with this model suggests that a variety of staff members working in primary care offices could learn to administer the counseling rather than relying exclusively on direct care providers. In addition, the success of incorporating telephone follow-up suggests that this intervention may be particularly appropriate for rural patients whose access to formal disease management counseling is often limited.

Because this study was designed to assess feasibility, it has a number of important limitations. These include lack of a control group, lack of objective clinical outcome measures, and difficulty interpreting language-based differences since language was perfectly confounded by site. Using research personnel to administer the study surveys and to conduct the intervention may have influenced participants toward offering desirable responses and could bias the measurement. However, such bias could occur at baseline and at follow-up. Additionally, using research personnel to perform the intervention limits our ability to assess the feasibility of implementing the intervention into existing clinical structures. Our intervention is currently being evaluated in community-based primary care clinics using their own staff to implement the intervention. This randomized, controlled effectiveness trial will use research personnel to assess outcomes and include objective clinical outcomes such as glycosylated hemoglobin and blood pressure.

\subsection{Conclusion}

Results from this study suggest that a literacy-appropriate self-management support package, including written educational materials and a brief counseling strategy, enhances self-management through improvements in practical knowledge and self-management behaviors. These successes were observed across literacy levels.

\subsection{Practice implications}

The Living with Diabetes guide and accompanying counseling process may be an effective strategy for teaching diabetes self-management skills in primary care settings. Since our materials were designed for both low-literacy and Spanish-speaking patients, clinics caring for these populations may find them particularly useful. Our results suggest that non-medical professionals can use appropriate educational materials and structure to teach patients effective goal-setting behavior. This process of using patient-centered materials and actionplanning may also translate to other chronic conditions requiring patient self-care.

\section{Supplementary Material}

Refer to Web version on PubMed Central for supplementary material.

\section{Acknowledgments}

We would like to thank Mary Bocchini, Katherine Davis, Adrianna Delgadillo, and James Joyner for the significant contributions each made to this study. We deeply appreciate the time and information offered to us by this study's patient participants.

Role of the funding source: The materials development and feasibility study described in this paper were supported by the American College of Physicians Foundation. Additional support for ASW's time was supplied by NIH T32 NR08856. Neither funding source participated in study design; in the collection, analysis, and interpretation of data; in the writing of the report; nor in the decision to submit the paper for publication. 


\section{References}

1. Ma J, Urizar GG, Alehegn T, Stafford RS. Diet and physical activity counseling during ambulatory care visits in the United States. Prev Med. 2004; 39:815-22. [PubMed: 15351551]

2. Glasgow RE, Eakin EG, Fisher EB, Bacak SJ, Brownson RC. Physician advice and support for physical activity: results from a national survey. Am J Prev Med. 2001; 21:189-96. [PubMed: 11567839]

3. Glasgow RE, Funnell MM, Bonomi AE, Davis C, Beckham V, Wagner EH. Self-management aspects of the improving chronic illness care breakthrough series: implementation with diabetes and heart failure teams. Ann Behav Med. 2002; 24:880-7.

4. Wagner EH, Bennett SM, Austin BT, Greene SM, Schaefer JK, Vonkorff M. Finding common ground: patient-centeredness and evidence-based chronic illness care. J Altern Complement Med. 2005; 11:S7-15. [PubMed: 16332190]

5. Schillinger D, Barton LR, Karter AJ, Wang F, Adler N. Does literacy mediate the relationship between education and health outcomes? A study of a low-income population with diabetes. Public Health Rep. 2006; 121:245-54. [PubMed: 16640146]

6. Schillinger D, Piette J, Grumbach K, Wang F, Wilson C, Daher C, Leong-Grotz K, Castro C, Bindman AB. Closing the loop: physician communication with diabetic patients who have low health literacy. Arch Intern Med. 2003; 163:83-90. [PubMed: 12523921]

7. Heisler M, Faul JD, Hayward RA, Langa KM, Blaum C, Weir D. Mechanisms for racial and ethnic disparities in glycemic control in middle-aged and older Americans in the health and retirement study. Arch Intern Med. 2007; 167:1853-60. [PubMed: 17893306]

8. Bandura, A. Self-efficacy: the exercise of control. New York: Freeman and Company; 1997.

9. Bodenheimer T, Lorig K, Holman H, Grumbach K. Patient self-management of chronic disease in primary care. JAMA. 2002; 288:2469-75. [PubMed: 12435261]

10. Marks R, Allegrante JP, Lorig K. A review and synthesis of research evidence for self-efficacyenhancing interventions for reducing chronic disability: implications for health education practice (part II). Health Promot Pract. 2005; 6:148-56. [PubMed: 15855284]

11. Hibbard JH, Stockard J, Mahoney ER, Tusler M. Development of the Patient Activation Measure (PAM): conceptualizing and measuring activation in patients and consumers. Health Serv Res. 2004; 39:1005-26. [PubMed: 15230939]

12. Mosen DM, Schmittdiel J, Hibbard J, Sobel D, Remmers C, Bellows J. Is patient activation associated with outcomes of care for adults with chronic conditions? J Ambul Care Manage. 2007; 30:21-9. [PubMed: 17170635]

13. Seligman HK, Wallace AS, DeWalt DA, Schillinger D, Arnold C, Delgadillo A, Bryant-Shilliday B, Bengal N, Palacios JL, Davis T. Developing low-literacy patient educational materials to facilitate behavior change. Am J Health Behav. 2007; 31:S69-78. [PubMed: 17931139]

14. Hibbard JH, Mahoney ER, Stockard J, Tusler M. Development and testing of a short form of the patient activation measure. Health Serv Res. 2005; 40:1918-30. [PubMed: 16336556]

15. Polonsky WH, Fisher L, Earles J, Dudl RJ, Lees J, Mullan J, Jackson RA. Assessing psychosocial distress in diabetes: development of the diabetes distress scale. Diabetes Care. 2005; 28:626-31. [PubMed: 15735199]

16. Sarkar U, Fisher L, Schillinger D. Is self-efficacy associated with diabetes self-management across race/ethnicity and health literacy? Diabetes Care. 2006; 29:823-9. [PubMed: 16567822]

17. Heisler M, Smith DM, Hayward RA, Krein SL, Kerr EA. How well do patients' assessments of their diabetes self-management correlate with actual glycemic control and receipt of recommended diabetes services? Diabetes Care. 2003; 26:738-43. [PubMed: 12610031]

18. Baker DW, Williams MV, Parker RM, Gazmararian JA, Nurss J. Development of a brief test to measure functional health literacy. Patient Educ Couns. 1999; 38:33-42. [PubMed: 14528569]

19. Parker RM, Baker DW, Williams MV, Nurss JR. The test of functional health literacy in adults: a new instrument for measuring patients' literacy skills. J Gen Intern Med. 1995; 10:537-41. [PubMed: 8576769] 
20. Davis, TC.; Kennen, EM.; Gazmararian, JA.; Williams, MV. Literacy testing in health care research. In: Schwartzberg, JG.; VanGeest, JB.; Wang, CC., editors. Understanding health literacy: implications for medicine and public health. Chicago: AMA Press; 2004. p. 157-79.

21. Davis TC, Long SW, Jackson RH, Mayeaux EJ, George RB, Murphy PW, Crouch MA. Rapid estimate of adult literacy in medicine: a shortened screening instrument. Fam Med. 1993; 25:3915. [PubMed: 8349060]

22. Lorig K. Action planning: a call to action. J Am Board Fam Med. 2006; 19:324-5. [PubMed: 16672687]

23. Bodenheimer T, Davis C, Holman H. Helping patients adopt healthier behaviors. Clin Diabetes. 2007; 25:66-70.

24. Gerber BS, Brodsky IG, Lawless KA, Smolin LI, Arozullah AM, Smith EV, Berbaum ML, Heckerling PS, Eiser AR. Implementation and evaluation of a low-literacy diabetes education computer multimedia application. Diabetes Care. 2005; 28:1574-80. [PubMed: 15983303]

25. Davis TC, Fredrickson DD, Arnold C, Murphy PW, Herbst M, Bocchini JA. A polio immunization pamphlet with increased appeal and simplified language does not improve comprehension to an acceptable level. Patient Educ Couns. 1998; 33:25-37. [PubMed: 9481346]

26. Ammerman AS, Lindquist CH, Lohr KN, Hersey J. The efficacy of behavioral interventions to modify dietary fat and fruit and vegetable intake: a review of the evidence. Prev Med. 2002; 35:25-41. [PubMed: 12079438]

27. Shilts MK, Horowitz M, Townsend MS. Goal setting as astrategy for dietary and physical activity behavior change: a review of the literature. Am J Health Promot. 2004; 19:81-93. [PubMed: 15559708]

28. Handley M, MacGregor K, Schillinger D, Sharifi C, Wong S, Bodenheimer T. Using action plans to help primary care patients adopt healthy behaviors: a descriptive study. J Am Board Fam Med. 2006; 19:224-31. [PubMed: 16672675]

29. DeWalt DA, Pignone M, Malone R, Rawls C, Kosnar MC, George G, Bryant B, Rothman RL, Angel B. Development and pilot testing of a disease management program for low literacy patients with heart failure. Patient Educ Couns. 2004; 55:78-86. [PubMed: 15476993]

30. Rothman RL, DeWalt DA, Malone R, Bryant B, Shintani A, Crigler B, Weinberger M, Pignone M. Influence of patient literacy on the effectiveness of a primary care-based diabetes disease management program. JAMA. 2004; 292:1711-6. [PubMed: 15479936]

31. Hibbard JH, Mahoney ER, Stock R, Tusler M. Do increases in patient activation result in improved self-management behaviors? Health Serv Res. 2007; 42:1443-63. [PubMed: 17610432]

32. Bradshaw BG, Richardson GE, Kumpfer K, Carlson J, Stanchfield J, Overall J, Brooks AM, Kulkarni K. Determining the efficacy of a resiliency training approach in adults with type 2 diabetes. Diabetes Educ. 2007; 33:650-9. [PubMed: 17684166]

33. Deakin TA, Cade JE, Williams R, Greenwood DC. Structured patient education: the diabetes XPERT Programme makes a difference. Diabet Med. 2006; 23:944-54. [PubMed: 16922700]

34. Siminerio LM, Piatt G, Zgibor JC. Implementing the chronic care model for improvements in diabetes care and education in a rural primary care practice. Diabetes Educ. 2005; 31:225-34. [PubMed: 15797851]

35. Glasgow RE, Whitesides H, Nelson CC, King DK. Use of the patient assessment of chronic illness care (PACIC) with diabetic patients: Relationship to patient characteristics, receipt of care, and self-management. Diabetes Care. 2005; 28:2655-61. [PubMed: 16249535] 
Table 1

Elements of the action plan process used in the intervention ${ }^{a}$.

I. Establish the action plan around four key questions

1. WHAT?

2. HOW MUCH? (of the activity)

3. WHEN? (time of day, or when during the week)

4. HOW MANY TIMES per week?

Here are some examples of plans answering the key questions:

- I will walk (WHAT) around the park in my neighborhood (HOW MUCH), before dinner (WHEN), 4 times a week (HOW MANY TIMES).

- I will cut back on my carbs (WHAT) by eating just the 1/4th plate portion (HOW MUCH) at dinner (WHEN), 5 times this week (HOW MANY TIMES).

II. Check confidence

It's important for the patient to be fairly confident that they will accomplish their entire plan. Using a scale of 0 (no way!) to 10 (absolutely!), we want a confidence level of 7 or more.

Example:

On a scale from 0 to 10 where 0 is not confident at all and 10 is completely confident, how confident are you that you will (then repeat the patient's action plan verbatim)?

If the patient answers below 7, the action plan should be changed, so the patient is more confident

- Do problem solving (What might get in the way of your accomplishing this plan? How can we change this plan so you'll be more confident?)

- Ask the patient to restate the modified Action Plan, then, ask their confidence level once more.

III. Follow-up

The aim of action plans is to practice better self-management, and make steady progress toward a goal

- What if the Action Plan is incompletely done? Ask why...sometimes patients have to change action plans because circumstances changed (ex. I sprained my ankle and couldn't do my walking plan, so I did chair exercises instead). In this case, praise the patient for being a good self-manager

- Emphasize what the patient was able to accomplish. Remember: confidence and self-efficacy are what we're trying to build

- Work with patient to make a more do-able Action Plan for next time

${ }^{a}$ Adapted from refs. [22,23]. 
Table 2

Participant demographic and health-related characteristics $(N=250)$.

\begin{tabular}{|c|c|}
\hline & Mean (range) \\
\hline Age & 56 years $(29-93)$ \\
\hline Time with diabetes & 9 years $(0-35)$ \\
\hline Last $\mathrm{A} 1 \mathrm{C}^{a}$ & $8.6(4.2-16.8)$ \\
\hline \multirow[t]{2}{*}{$\mathrm{BMI}^{b}$} & $34.7(12.9-73.4)$ \\
\hline & Number $(\%)$ \\
\hline \multicolumn{2}{|l|}{ Gender } \\
\hline Female & $162(64.8 \%)$ \\
\hline Male & $88(35.2 \%)$ \\
\hline \multicolumn{2}{|l|}{ Race/ethnicity } \\
\hline African-American & $112(44.8 \%)$ \\
\hline Hispanic & $83(33.2 \%)$ \\
\hline Caucasian & $55(22.0 \%)$ \\
\hline \multicolumn{2}{|l|}{ Language } \\
\hline English & $173(69.2 \%)$ \\
\hline Spanish & $77(30.8 \%)$ \\
\hline \multicolumn{2}{|l|}{ Insurance } \\
\hline Self-pay & $119(47.6 \%)$ \\
\hline Medicaid & $66(26.4 \%)$ \\
\hline Medicare & $58(23.2 \%)$ \\
\hline Private insurance ${ }^{c}$ & $40(16.0 \%)$ \\
\hline \multicolumn{2}{|l|}{ Education } \\
\hline$<$ High school & $109(43.6 \%)$ \\
\hline High school & $85(34.0 \%)$ \\
\hline Some college & $38(15.2 \%)$ \\
\hline College degree+ & $18(7.2 \%)$ \\
\hline \multicolumn{2}{|l|}{ Health literacy } \\
\hline Adequate & $142(56.8 \%)$ \\
\hline Marginal & $36(14.4 \%)$ \\
\hline Inadequate & $72(28.8 \%)$ \\
\hline Takes insulin & $109(43.6 \%)$ \\
\hline Takes oral medications & $204(81.6 \%)$ \\
\hline Self monitors glucose & $211(84.4 \%)$ \\
\hline Has regular MD & $157(62.8 \%)$ \\
\hline Hospitalized during the past year & $72(29.0 \%)$ \\
\hline
\end{tabular}

${ }_{n=243}$.

$b_{n=249}$.

${ }^{c}$ Insurance categories not mutually exclusive. 


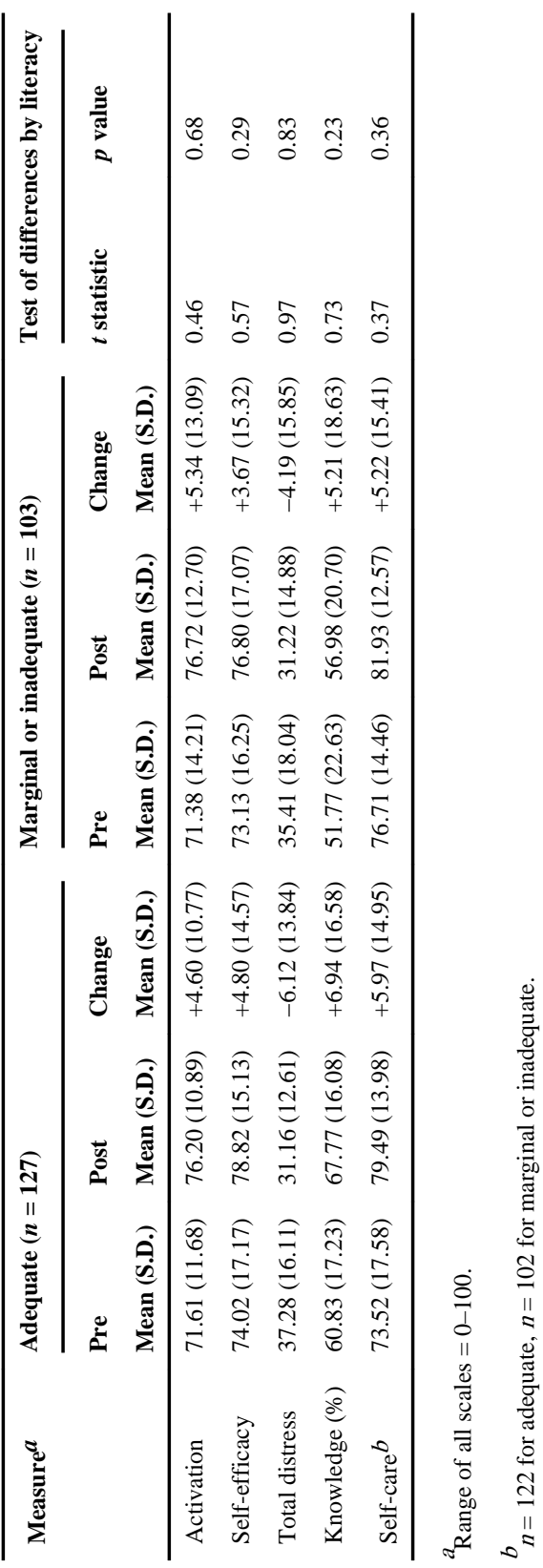




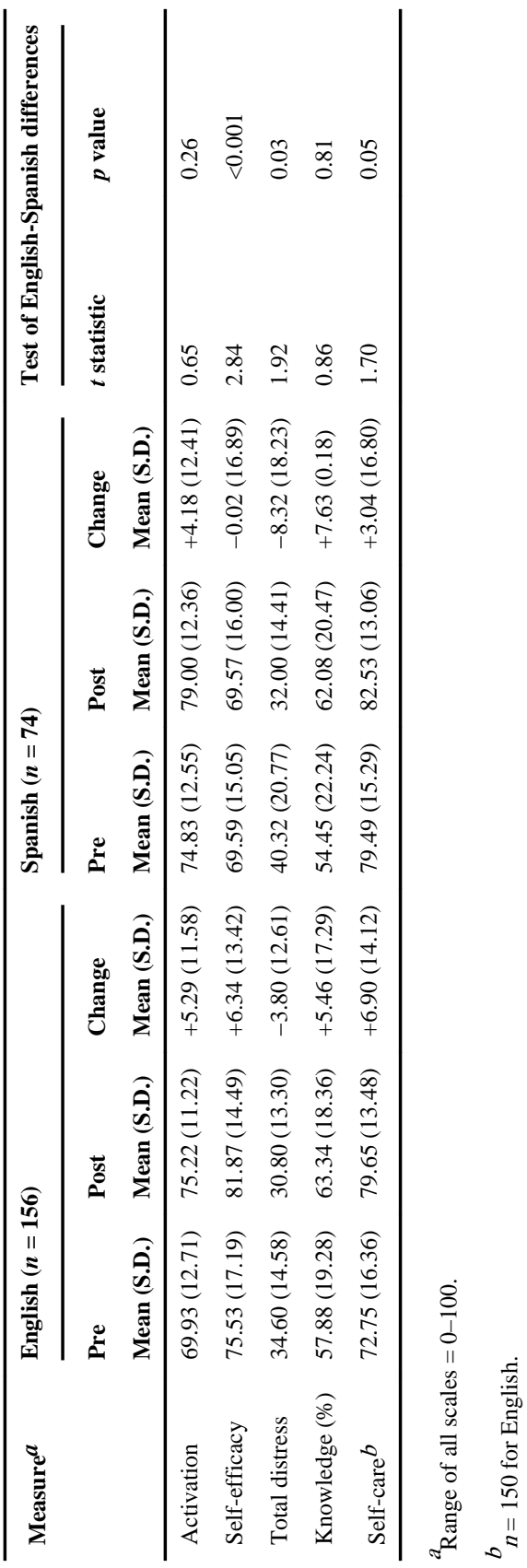

